\title{
New Cultural Interfaces on the Gallerie dell'Accademia in Venice
}

\author{
Francesco Borella \\ Isabella Friso \\ Ludovica Galeazzo \\ Cosimo Monteleone \\ Elena Svalduz
}

\section{Abstract}

In the digital age, museums have seen a significant expansion of the spaces and tools for disseminating knowledge. Gallerie dell'Accademia had commissioned a permanent and multimedia video that summarized the results of the interdisciplinary research developed within Visualizing Venice - S. Maria della Carità, S. Agnese, and the Gesuati, three insulae make one - that told about the history of the urban and architectural transformations of the insula. Since it is not a totally immersive installation, some years later Gallerie asked to make some changes to the previous animation to allow a greater interactivity between user and observed data. In order to keep the visitor's attention threshold high and active, different sections of short duration have been introduced, which can be interrogated and activated by sensors, while a Sound Shower system facilitates the understanding of the multimedia story through the listening of a narrator's voice.

Keywords

virtual reality, digital model, database, interaction, immersivity.

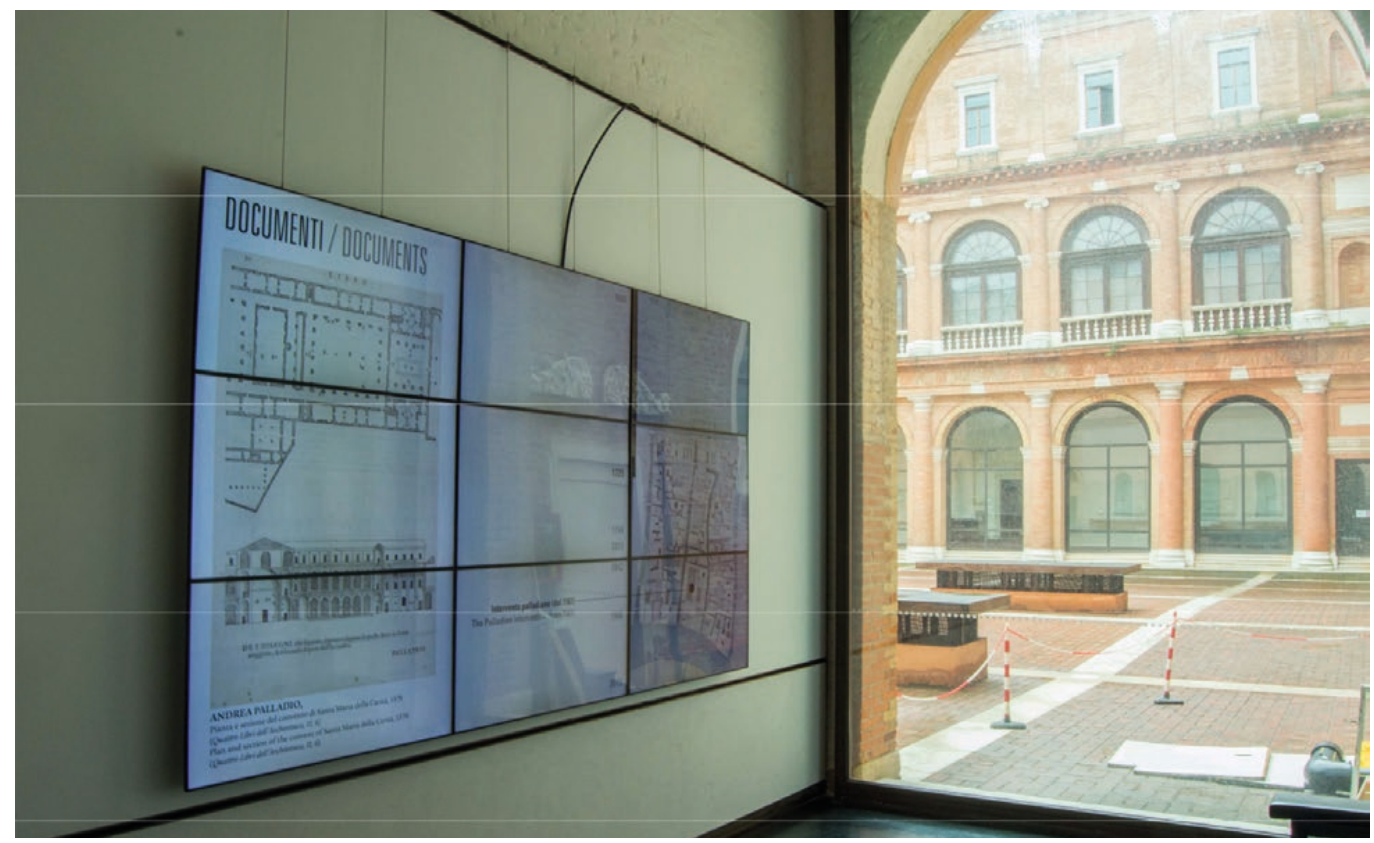




\section{Venice in Motion: the Site of the Gallerie dell'Accademia Between New Media and History}

The idea of Venice as a city constantly in motion has been recognized for some time now, so much so that it has become a truly significant feature of its own image. Movement does not only concern individuals, goods, and objects, but also its urban and architectural space. This pertains to the transformation of buildings and the relationship between land and water, but also - and equally importantly - it involves the functional use of space, the articulation of collective facilities, and the city's appearance. To these extents, the area of the Gallerie dell'Accademia represents an exemplary case study of inquiry. Located on the southern margin of Venice, in a transitional space stretching between the Grand Canal and the Giudecca Canal, the site consists of three insulae named for the ancient religious complexes that once moulded its space: Sant'Agnese, the Gesuati, and Santa Maria della Carità. The latter, which consisted of the church, the adjacent monastery of the Lateran Congregation of the Canons Regular of Saint Augustine, and the Scuola Grande, was converted at the beginning of the nineteenth century to accommodate the Academy of Fine Arts and later, in 1817, the Gallerie dell'Accademia [Codello 2017]. The history of these institutions and pertinent buildings has been widely investigated by art and architectural historians who devoted particular attention to Andrea Palladio's design for the renovation of the monastery of the Carità [Modesti 2005, 2005b]. However, the long-term history of today's site of the Gallerie dell'Accademia and its interwoven relationships with its surrounding urban fabric have remained largely unstudied, in part because of the difficulty to show the public how the museum was inserted into existing spaces and in what way these places have changed over time [Svalduz 2017].

If looking today from above, the area emerges as a compact and uniform site, but actually its topography is the result of a process of urban and architectural stratifications that spans a thousand-year history. Until the beginning of the nineteenth century, the settlement was designed by an articulate system of waterways, which included two straight canals - the Rio della Carità and Rio di Sant'Agnese - crossing the site longitudinally and flanking both sides of the Lateran Canons' complex. As part of the process of modernization undertaken in the aftermath of Napoleonic rule, the two watercourses were filled in, while the erection of a new bridge over the Grand Canal definitely brought the entire area out of isolation by ensuring a rapid pedestrian link to the rest of the city [Galeazzo 20।8] [I].

These changes profoundly altered the urban settlement's configuration, as well as the visual perception of the ancient buildings, especially of those belonging to the Lateran monastery. What had previously been a sort of fortress surrounded by water gradually became integrated into the city [di Lenardo 20 13]. In addition, the conversion of religious buildings into secular places eventually led to an invasive campaign of renovation of the ancient structures, which were stripped of their decorations to avoid any visual-mental connection to the former ecclesiastical complex.

The emerging dialogue between new media and traditional historical research offered the multidisciplinary team the option of experimenting an innovative approach to visualizing and communicating these historical changes. The video 'The History of a Site and its Transformations: From Carità to the Gallerie dell'Accademia' was created to exploit the affordances of emerging technologies as a powerful tool for giving visitors a simplified and comprehensive understanding of the area's elaborate changes over the centuries. The project had two overlapping objectives: to shed light on the urban and architectural transformations of the urban site while focusing on the impact these modifications had in the land - and water - based Venetian traffic systems and to visually represent the relationship between the previous structures and the present spaces of the museum to help visitors understand the origins of the complex. The philological reconstruction of this large section of the city was based on the collection of a broad scope of historical sources and identification of a series of significant chronological phases that represent many temporal snapshots in the history of the insula's transformation. These span over five centuries and help visualize the tight bond between space and architecture. Beginning with the renowned bird's-eye view of Venice by Jacopo de' Barbari (1500), the video then reconstructs the eighteenth-century shape of the 
newly-built church of the Gesuati as well as the spatial organization of the monastery of the Carità through both cartographic and iconographic sources. These encompass the first city's map of Venice by Ludovico Ughi ( I729), several detailed drawings executed by local magistrates, a sequence of Canaletto's paintings, as well as some precious surveys elaborated by the proto Pietro Angelo Fossati immediately after the suppression of the Augustinian monastery in 1793. Napoleonic (|808-|8|I), Austrian (I838-|842) and Austro-Italian (I8671913) cadastral maps were instead crucial for mapping nineteenth-century transformations of the waterway and pedestrian system [Galeazzo, Pedron 20I4].

While the goal of the video is primarily didactic and informative, showing the transformation of the area from the early Renaissance to the twentieth century, it also allows users to physically experience the transformation of water-courses into pedestrian paths through a virtual trip along the now filled-in canals, it brings also a contextualized understanding of how an amphibious city like Venice was subjected to a gradual process of land reclamation.

\section{Digital Representation of Architectural and Urban Changes Overtime}

Cinema and photography embodied the main cultural interfaces of the 20th century, tools through which it was possible to describe the movement. With the advent of digital representation, virtual reality has 'stolen the scene' from previous forms of communication. According with other devices, the monitor has become more and more important since it constitutes the limit of the virtual vision, the tool with which the user/observer must interface an illusory space through a sort of virtual window. It is a threshold from which to experience a mosaic of information perceived from multiple points of view referring to many different reading planes. The main novelty of the man-computer-culture interface lies in the revolutionary way in which machines present data and allow to interact with them [Manovich 2009].

The installation created for the Gallerie dell'Accademia involves the projection of a digital movie on a videowall [2]. The first frames of this movie serve to contextualize the three ancient insulae as they were in the 16th century urban fabric. The digital reconstruction was carried out through a process backwards in time starting from the actual state of the insula. The narrative structure and the storyboard of the installation follow instead a linear exposition of the events, which allows a reading without interruptions and reversals the chronological order of the events. The story retraces the historical phases starting from I 500 up today. The large amounts of documents, historical data, literary and graphic sources constitute the documentary substrate on which this work is based.

The starting point of the modeling phase is the state of the insula as we did in 2015, when the original movie was created. Maps, engravings, drawings, surveys, chronicles, photographs and publications were added to the virtual platform.

The next step concerns the identification of the historical moments in which the most significant transformations of the urban fabric occurred, identifying six main historical phases summarized here and appropriately arranged with historians, which provided the starting dates: I500, I729, I 794, I8 I I, I842, I 906 up to 20 I5. Where the information on individual buildings was not sufficiently clear and comprehensive to develop a detailed model, we preferred to omit its representation, opting for a volumetric abstraction of the building rather than originating an arbitrary interpretation, not very rigorous from a scientific point of view. In the movie, the concept of time is explicitly expressed through a timeline, always visible on the screen, which attests the chronological sequence of events throughout the centuries considered. The timeline, arranged vertically, determines the page layout. Moving forward chronologically, it ideally cuts the screen into two parts (one twice wider than the other), following the horizontal division defined by the width of the monitors that make up the video wall. The size of the monitors and their mutual approach define the standard layout, the guidelines of an ideal and a modular grid, that help us to insert the documents. On the right, the visitor can see the plan of the insula, a static image accompanied by some tags that highlight the main urban and architectural changes occurred over time; on the left, instead, all the documents appear in a fading succession (fig. 2). This documents are the data 
that allowed us to model the urban situation in a precise historical phase. This roundup of static images concludes with a render of the digital model at the specific year.To interrupt the static images of the movie we set a virtual tour around the insula, as it was in 1794, along the canals now filled-in. The animation is introduced by a plan that shows the path of the camera around the insula della Carità during the tour. Suddenly the timeline, moving to the right side, gives the space to a full-screen movie: a representation within the representation, in which the viewer is involved in the perception of urban spaces from a today unusual and no longer available perspective that coincides with that of a visitor who is navigating the canals using a gondola, exactly as a citizen of the past centuries. The camera, simulating the eye of the observer, moves through two canals - the Carità and Sant'Agnese - in a position slightly above the water level, stabilizing a perspective horizon that coincides with a line just a bit over the walking surface. The movement of the camera inside the virtual environments is necessary to overlap a document directly on the 3D model to explain the reconstruction of some elevations of the buildings that face the canals, of which we have a precise document, like the precious surveys made by the engineer Pietro Angelo Fossati in 1793. These drawings can be rightly positioned only in a virtual 3DF model that takes into account the movement of an observer floating on a boat. Following the idea of updating our first installation to new technologies, the same team of scholars has recently proposed to the museum an integration of the display with other in-depth historical studies to offer visitors a broader knowledge of the site. Users will be invited to choose between different lightening chapters, which are diversified basing on analysis, topic, and disciplinary approaches [3].

\section{Conclusions}

Recently the Gallerie dell'Accademia has asked for some changes to the previous animation, the aim was to improve the interactivity between user and data. At the moment the ad hoc app, is a loop animation. But in the next future using an interactive menu by a gesture system it will be possible to chose which kind of documents it is going to visualize: digital videos, images or texts. The app keeps in connection the input and output devices linked to the PC in order to allow to check how to visualize documents.

The Kinect's cameras allow to the user to interact trough e gesture system using only movements by hands and arms, without using fisical devices that control the movements. The open hand pointed to the monitor will allow to activate a main menu, moving on the differente voices and choseeing the preferit section. In the same waythe user will come back to the principal animation. Finally the sound shower system will allow e directional and localized diffusion of audio track of videos, in order to obtain a more immersive experience. This tool conveys to the sound in a limited area of the room not to disturb the visitors in adjacent exhibition spaces (fig. 3).

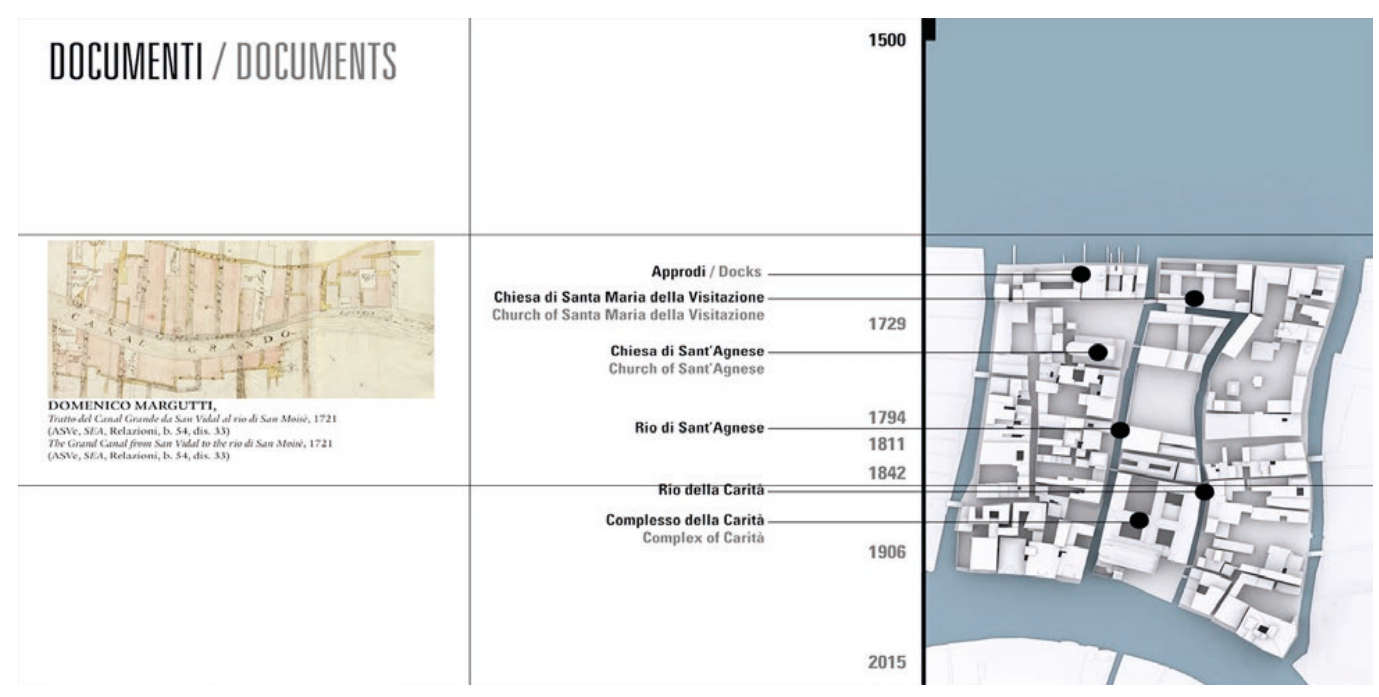


Fig. 2. Devices of the new interactive installation.

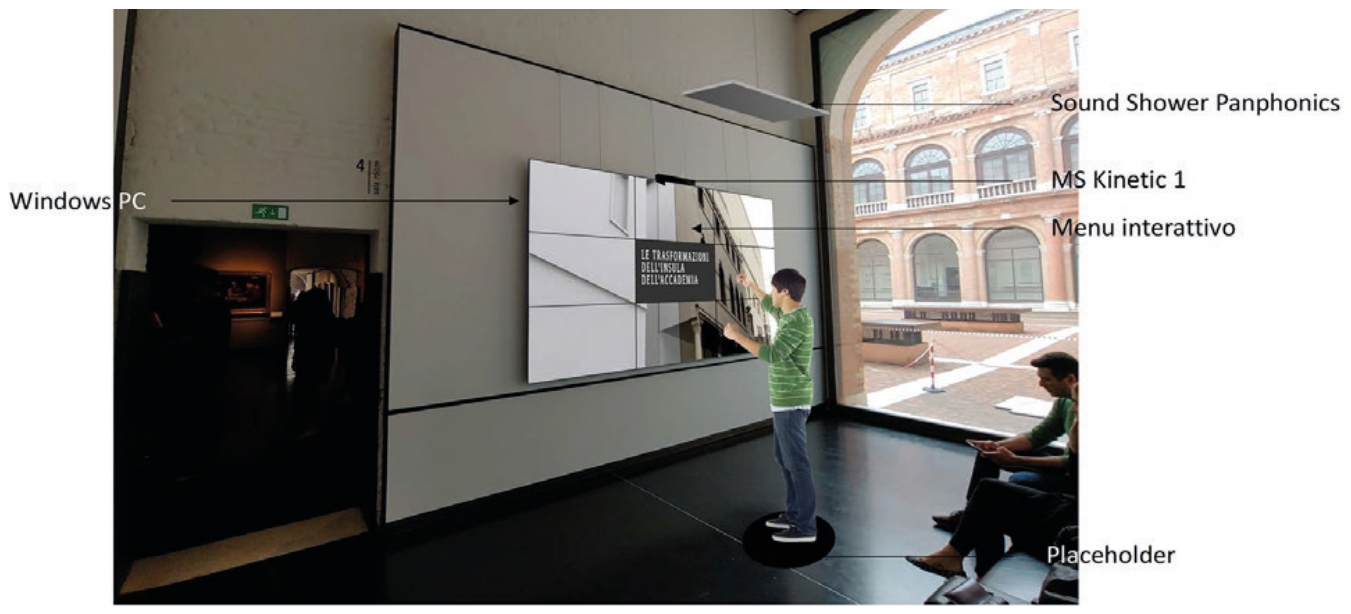

The introduction of an interactive action makes between visitor and installation made the reading and the learning of the urban and architectural story of the of the insula della Carità more involving. Operations of this kind can be considered as alternative tools, available to museums, for a transversal dissemination of knowledge, but this implies that the role of the representation of architecture and the city is called to respond to new challenges [4].

\section{Notes}

[I] The Carità and Sant'Agnese canals were filled in 1817 and 1863 respectively. In 1854, the English engineer Alfred Henry Neville built a suspended iron bridge, which was replaced in 1933 by a supposedly 'temporary' wooden bridge by Eugenio Miozzi.

[2] Each liquid crystal monitor is 46' in 16:9. The assembly of the devices provides for a $3 \times 3$ arrangement, i.e. three monitors along the horizontal direction and three along the vertical one set on one of the longitudinal walls of room 4, occupying a total area of 5.238 square meter.The realization of the video assembly was achieved thanks to funding and sponsorship from Samsung Electronics Italia s.p.a. and Ventian Heritage, which supplied the monitors necessary for the projection of the images.

[3] These narratives will include: the investigation of the insula dell'Accademia as an area between various ecclesiastical communities; the digital reconstruction of Andrea Palladio's design for the monastery of Carità and its relation with the realized buildings of the museum; and the nineteenth- and twentieth-century architectural transformations of both the exterior and interior spaces of the Lateran Canons' complex, made to house the Academy of Fine Arts and the Gallerie dell'Accademia. A specific chapter will also be devoted to the campo (square) that faces the Grand Canal and its ancient functions of cemetery, docks for boats, place of humanistic encounters, space for ceremonies and events.

[4] Venice in Motion:The Site of the Gallerie dell'Accademia between New Media and History was written by L. Galeazzo and E. Svalduz; Digital representationo of architectural and urban changes overtime was written by I. Friso and C. Monteleone; Conclusion was written by F. Borella.

\section{References}

Codello Renata (ed.) (2017). Venezia: la Grande Accademia. Architettura e restauro. Milano: Electa.

di Lenardo Isabella (20।3). From calle to insula:The Case of Santa Maria della Carità in Venice. In Calabi Donatella (ed.). Built City, Designed City, Virtual City. Roma: Croma-Università degli studi Roma Tre, pp. I53-I 68.

Galeazzo Ludovica (20 I8). Storia e trasformazioni di uno spazio liminale: l'insula di Santa Maria della Carità tra XV e XX secolo. In Ateneo Veneto, CCV (17/II), pp. 19-5I.

Galeazzo Ludovica, Pedron Marco (20|4). Visualizing Venice. Mappare e modellare la storia urbana: il caso dell'insula dell'Accademia. In Adorno Salvatore, Cristina Giovanni, Rotondo Arianna (eds.). Visibilelnvisibile. Percepire la città tra descrizioni e omissioni, proceedings of the 6th AISU Conference in Catania, vol.VII. Catania: Scrimm Edizioni, pp. 200 I-20 I 2.

Manovich Lev (2009). Il linguaggio dei nuovi media. Milano: Edizioni Olivares.

\section{Authors}

Francesco Borella, Art Director Omniaweb s.r.l, francesco.borella@omniaweb.it Isabella Friso, Dept. of Architecture and Arts, luav University of Venice, ifriso@iuav.it

Ludovica Galeazzo, Villa ITatti,The Harvard University Center for Italian Renaissance Studies, ludovica.galeazzo@gmail.com Cosimo Monteleone, Dept. of Civil, Environmental and Architectural Engineering, University of Padua, cosimo.monteleone@unipd.it Elena Svalduz, Dept. of Cultural Heritage, University of Padua, elena.svalduz@unipd.it 
